\title{
Ocho mujeres poseídas: trayectorias de feminidades y particularidades ${ }^{*}$
}

Andrea León**

Recibido: 27 de septiembre de 2019 • Aprobado: 24 de octubre de 2019

\section{Resumen}

Ocho mujeres poseídas, obra de Tennessee Williams (1977), presenta itinerarios y desavenencias de diferentes subjetividades femeninas. Así, en su relato subyacen elementos discursivos que ofrecen una aproximación a la noción de un feminismo actual, que tiene como eje principal la autonomía, elemento que se presenta desde tres vertientes: social, sexual y económica. De esta manera, usando el análisis del discurso literario como herramienta interpretativa, se abordan algunas particularidades del feminismo, entendido como un movimiento que insiste en la reinterpretación de la realidad situada en este momento histórico y cultural.

Palabras clave: autonomía, feminismo, imaginarios sociales, machismo, sexismo.

Artículo de reflexión. Citar como: León, A. (2020). Ocho mujeres poseídas: trayectorias de feminidades y particularidades. Análisis, 52(96), 81-94. Dol: https://doi.org/10.15332/21459169/5330

Docente investigadora. Instructora del Servicio Nacional de Aprendizaje - SENA- Regional Bogotá. Magíster en Comunicación y Educación de la Universidad Distrital Francisco José de Caldas. Correo electrónico: andare0203@ gmail.com. ORCID: https://orcid.org/0000-0002-1358-8419 


\section{Eight mortal ladies possessed: trajectories of femininities and particularities}

Andrea León

\section{Albstract}

Eight mortal ladies possessed, the work of Tennessee Williams (1977), presents itineraries and disagreements of different female subjectivities. Thus, in his story there are discursive elements that offer an approach to the notion of a current feminism, whose main theme is autonomy, an element that is presented from three aspects: social, sexual and economic. Therefore, using the analysis of literary discourse as an interpretive tool, some particularities of feminism are addressed, understood as a movement that insists on the reinterpretation of reality set in this historical and cultural moment.

Keywords: autonomy, feminism, social imaginary, machismo, sexism. 


\title{
Eight Mortal Ladies Possessed : trajets de féminités et de contraintes
}

\author{
Andrea León
}

\section{Résumé}

Eight Mortal Ladies Possessed, l'œuvre de Tennessee Williams (1977), retrace l'itinéraire et les troubles de quelques subjectivités féminines. Le récit contient, en effet, des éléments qui peuvent évoquer les notions du féminisme actuel, dont l'axe principal est l'autonomie sociale, sexuelle et économique. Dès lors, en engageant l'analyse du discours littéraire comme outil d'interprétation, on se propose de saisir un certain nombre de particularités du féminisme, entendu comme un mouvement qui insiste sur la réinterprétation de la réalité située dans notre propre moment historique et culturel.

Mots clés: autonomie, féminisme, imaginaire sociaux, machisme, sexisme. 


\section{Introducción}

En 2018, la Real Academia Española (RAE) ${ }^{1}$ decidió darle significado al vocablo feminazi; ya en diferentes plataformas se puede encontrar - lo que invita a usar- dicho término. Con excusas desde lo normativo frente a los neologismos, la RAE encontró una salida para zafarse del debate; sin embargo, desde el discurso institucional se entrevé que dicho término, erróneamente, contiene el mismo valor semántico que el feminismo, lo que en gran medida repercute en las manifestaciones sociales. Como recuerda Ríos (2010): "el lenguaje es una herramienta que puede usarse para explorar y manipular el ambiente social y establecer estatus y relaciones dentro de él" (p. 21).

Lo mismo sucede con el vocablo hembrismo, que aparece como contraposición al de machismo; es decir, si el machismo es la ideología de pensar que el macho es superior, el hembrismo definirá que la hembra es superior al hombre. Rivera (2014), al respecto, afirma que "el hembrismo es un invento machista para que las mujeres rechacemos la emancipación de otras" (párr. 11); además, al asumir este término, se estaría asimilando que históricamente el hombre ha sido sometido a las mismas desigualdades que las mujeres.

Respecto al sexismo, es común que se confunda con adjetivos referidos a la estimulación sexual. Sin embargo, el sexismo es "una actitud discriminatoria, dirigida a las personas en virtud de su pertenencia a un determinado sexo biológico, en función del cual se asumen diferentes características y conductas" (Garaigordobil \& Donado, 2011, §1). Por ejemplo, si se nace hombre se lo obliga a no expresar sus sentimientos, a que le guste el sexo... El hecho de no dejar el cuidado de los niños a los hombres por temor a que exista un abuso sexual es una muestra de cómo los estereotipos de género logran definir a una persona; en este caso, por el hecho de ser hombre se lo define como "depredador sexual": expresiones como "todos los hombres son infieles", "severa flor", "él sí ayuda en casa" o "el hombre en la cocina huele a mierda de gallina" son representaciones de un pensamiento sexista.

Si en virtud de ser mujer se la obliga a ser dócil, recatada, ocuparse del hogar, etc., se estaría ante una forma de sexismo, porque es lo que se le reclama según su sexo biológico. De esta manera, si a una mujer se le dice desde niña que "el hombre propone y la mujer dispone", se afirma que el hombre pertenece al mundo de lo racional, de lo cultural, al mundo de las ideas; mientras que la mujer pertenece a lo físico, a la naturaleza, a lo irracional, está a merced del hombre.

Apelando a la semiótica del lugar, el almacén Fallabella hace uso de un discurso sexista: los olores florales se integran en la sección femenina, que tiene una iluminación clara; allí hay variedad en accesorios y prendas de vestir (resaltan vestidos y faldas), con numerosos espejos, y es significativamente más grande

1 Cuenta de Twitter de la RAE: \#RAEconsultas La voz «feminazi» (acrónimo de «feminista» + «nazi») se utiliza con intención despectiva con el sentido de «feminista radicalizada). [21 de abril de 2018] 
que la sección de hombres. En esta última, la iluminación es opaca, con pocos espejos; además, se encuentra junto a la sección de tecnología y el ambiente es invadido por olores cítricos o amaderados. Ejemplos similares acontecen en babyshowers, fiestas de 15 años (para las adolescentes), celebraciones de 18 años (para los jóvenes), matrimonios, etc.

Por otra parte, quisiera abordar el feminismo $-\mathrm{y}$ tal vez ahondar en el significado de dicha manera de ser y estar en el mundo- haciendo un análisis de la obra de Tennessee Williams (1977), intitulada Ocho mujeres poseídas. Este relato encuentra su poder discursivo en el feminismo, lo que me da elementos para realizar una aproximación a dicha noción como apuesta política que demanda autonomía por parte de los sujetos que habitan la sociedad desde determinadas significaciones imaginarias.

Para lograr tal aproximación, es necesario aceptar que el sexismo ha afectado más a las mujeres que a los hombres, históricamente hablando. Además, es pertinente recordar que una de las formas en las que se presenta el sexismo es el machismo. De esta manera, para abordar el feminismo en la obra de Williams (1977), se hablará de prácticas desiguales por las que han tenido que sobrevenir las mujeres allí narradas, a quienes se les ha dicho cómo deben actuar, qué deben desear, a qué deben temer y cómo deben entender la felicidad.

\section{Moldeando mujeres desde la institucionalidad: familia, escuela, religión y medios de comunicación}

En la primera historia, Feliz 10 de agosto, se encuentran en escena dos personajes principales: Horne y Elphinstone. Elphinstone insiste en mantener recuerdos maternales en casa. En una discusión, Horne le reclama a Elphinstone: "Aquí todo es de tu madre o de tu abuela o de la madre de tu abuela" (pp. 17-18). Elphinstone se refugia en reliquias familiares de Wedgwood e Haviland, objetos que representan una línea generacional de mujeres instruidas en pensar que solo hay una forma de ser mujer desde lo que le provee un apellido. Aferrarse a los objetos de sus antepasados femeninos refiere un profundo valor psicológico en el proceder de Elphinstone, encontrándose en la disyuntiva de definirse desde su particularidad ("la nueva mujer") o desde su herencia materna (permanecer con las reliquias femeninas). Ella prefiere quedarse con la primera.

En una conversación de Elphinstone con su mamá, esta última le pregunta: “¿Qué diablos es Horne? ¿Acaso esa Horne no tiene un nombre de pila con el que puedas referirte a ella?", a lo que Elphinstone contesta: "Somos dos profesionales solteras y las profesionales solteras se llaman entre sí por los apellidos" (p. 22). Esto demuestra que el imaginario social frente al tratamiento de mujeres es heteronormativo y, como tal, produce inestabilidad emocional a quien esté socializado en esta dinámica. Así, la madre de Elphinstone, al ver que su hija se sale de los preceptos sociales, se desestabiliza y le reclama. 
En este punto, De Beauvoir (1981) alude a que "la familia es un nido de perversiones" (p. 20); es decir, desde la familia se incluyen determinadas maneras de proceder según el sexo con el que se nace. Así, los roles, tanto de hombres como mujeres, se van impulsando desde pautas de crianza que dicen cómo se debe ser en la sociedad, presentando a la mujer como sumisa, encargada del hogar y de los hijos. En el caso de Completada, la señora Sally está preocupada porque su hija aún sigue soltera:

Aunque la señorita Rosemary McCool se aproximaba a los veinte años, aún no había tenido su primera menstruación. Esta circunstancia era verdaderamente digna de que su madre viuda aplazara su intención de presentar aquella temporada a su única hija a la sociedad [...]. Sally era una dama [...] por lo que siguió adelante con sus planes para la presentación de su hija en sociedad. (pp. 113 y 117)

La preocupación ante el no matrimonio deviene de la idea de creer que la mujer depende del hombre para lograr el bienestar económico y el placer sexual. Sin embargo, el lesbianismo aparece como contraposición a dicha suposición. Al respecto, Castellanos (2011) afirma que "la presuposición de que la heterosexualidad es natural y que desviarse de ella implica caer en una anomalía monstruosa, es en el fondo una posición de poder y una premisa para la instauración de un sistema coercitivo" (p. 132), que impide entender otras maneras de relacionarse:

No comprendo esta eterna mención de Horne, siempre Horne - se lamentó su madre- No he oído decir otra palabra que Horne durante diez años seguidos [...]. ¡Oh, Dios mío! En esto hay algo peculiar, siempre lo he sospechado ¿Qué significa? [...]. ¡Opino que es ridículo, hacer una religión, una mística absurda, del hecho de haber sido alumna de esa pretenciosa institución de la elegancia afectada! (p. 15)

Al colegio que se refiere Horne es a la institución a la que asistió Elphistone; específicamente se refiere al Sarah Lawrence, colegio creado en la primera mitad del siglo XIX, en Estados Unidos. Este lugar fue creado para dar instrucción a mujeres en artes y humanidades. Se observa, entonces, que la institucionalidad - representada en la educación escolar - forma a la mujer acerca de cómo debe serlo.

En esta misma discusión, Elphinstone le replica a Horne: "Algunas de mis amigas se sintieron algo desconcertadas por tu tendencia a usar un lenguaje obsceno, incluso en las ocasiones menos apropiadas" (pp. 15-16), manifestando que el lenguaje de una mujer no debe ser agresivo ni soez. Kinder (2017), en Empowering Women Now, escribe lo siguiente: "La obscenidad es uno de los rasgos menos propios de una dama" (§ 2.1.).

Una de las grandes instituciones que promueven formas de socialización heteronormativas es la Iglesia, donde también habita la doble moral y la hipocresía. 
Tennesse, usando como voz narrativa a la principessa Lizabetta, expresa: "mientras estuve en aquel convento aprendí que hay usos para las velas distintos de la iluminación de la mesa de la cena, pero aquello era faute de mieux" (p. 42). Esta última expresión se traduce como "a falta de algo mejor". La siquiatría del siglo xIX usaba esta expresión para referirse a la elección por parte de un sujeto de mantener relaciones sexuales con una persona de su mismo sexo, cuando le era imposible conseguir una pareja del sexo opuesto (Moya, 2010).

Los mass media inducen a una feminidad normativa: joven, delgada, delicada... la que está de moda, la inaceptable. En Sabbatha y la soledad, el narrador afirma:

Y fue hacia ese arroyo esperando inconscientemente que sus apagados murmullos de excitación evocarían voces del pasado que solía oír, por ejemplo, cuando entraba en cierto restaurante francés del Village en los tiempos en que Sabbatha era una figura eminente en el mundo literario y en el de la moda [...]. Pero [...] cuando entró y vio que su mesa habitual le había sido usurpada por unos jóvenes hirsutos y barbudos.

-Oh señora- contestó el maître. —Se trata del joven poeta Ginsberg y otros dos; no puedo trasladarles [...]. Verá, ahora están muy, muy de moda. Últimamente han aparecido en las cubiertas de varias revistas importantes-. (pp. 89-92)

Riveros (2017) afirma que "una vez que la psique adopta la forma exigida por las significaciones imaginarias de la sociedad (o de la institución que la encarna) es que el individuo se convierte en un producto de la institución social" (p. 96), siendo el individuo mismo quien persigue cumplir el mandato social. Desde esta perspectiva, no se puede hablar de autonomía social, en tanto el sujeto se encuentra acrítico y obediente ante las normas y reglas que han sido creadas en los espacios de socialización. A propósito, Castoriadis (2014) insiste en que la autonomía, ya sea social o individual, es darse uno mismo sus leyes, es la aparición de un eidos nuevo en la historia del ser: un tipo de ser que se da a sí mismo, reflexivamente, con sus leyes de ser.

\section{Mujer: ser erótico, placer y deseo}

A la sexualidad femenina se la ha inscrito desde lo suave, lo sensual y lo no genital, de tal manera que a la mujer se la obliga - desde la violencia simbóli$\mathrm{ca}-\mathrm{a}$ renunciar al placer y al reconocimiento de su cuerpo erótico, incidiendo significativamente en su comportamiento sexual, ya que el cuerpo es visto desde el pecado, lo prohibido. Basta ver las implicaciones sociales de una mujer al afirmar que se masturba, implicaciones distantes ante el mismo comportamiento por parte de los hombres.

En la historia de La señorita Coynte de Greene, se logra ver a una mujer de 30 años que: 
No sentía la menor turbación [...] y esta vez no fueron los nudillos, sino las yemas de sus dedos las que rozaron, sin ninguna pretensión de gesto casual, la prominencia oculta bajo la parábola vertical de la tirante bragueta de Sonny Bowles. (p. 68)

Así, la señorita Coynte es la representación literaria de una mujer que toma decisiones propias sobre su vida sexual, asume el control de su cuerpo y el placer emerge desde lo que a ella la haga sentir bien, no desde lo heteronormativo donde el hombre somete a la mujer. Para bell hooks² (Watkins, 2017), "la sexualidad de las mujeres fue un catalizador fundamental para el movimiento feminista, pues permitió reconocer los cuerpos de las mujeres, defender el derecho a elegir, a ejercer más libremente su sexualidad" (p. 17). En La señorita Coynte de Greene se relata lo siguiente:

Cuando Sonny volvió de allí una semana después, se encontró sin empleo [...], había sido reemplazado por sus dos hermanos menores, un par de gemelos llamados Mike y Moon. Estos gemelos eran idénticos — ¿has sido tú, Mike?-, solía preguntar la señorita Coynte [...]. - No, señora, yo soy Moon, señorita Coynte. (p. 70)

Aunque es evidente el abuso de poder de la señorita Coynte sobre sus empleados, se hace visible la expresión de la sexualidad de dicha mujer desde la perspectiva del deseo y la pasión. De este modo, se entiende que la libertad sexual se desarrolla desde el cuerpo como el elemento (mediador del amor propio) que debe sentirse y pensarse desde el yo como mujer, no desde dinámicas en las que fuimos socializadas y a las que debemos asistir desde la ritualización del complacer al hombre siempre.

Butler (2002) explica que el cuerpo se desenvuelve en un contexto determinado, y es a partir de estas formas como se va construyendo la identidad. Así, el hecho de poder decidir sobre el cuerpo debe indicar a las mujeres que esas decisiones son derechos básicos del ser humano en tanto el cuerpo se habita, y es a este al que atraviesan las relaciones de poder. De esta manera, al empoderarse del propio cuerpo, se asume una posición ideológica diferente a la construida culturalmente:

En septiembre hubo un concurso de baile en el que participaron doce parejas, pero a los dos minutos todas las parejas se retiraron de la pista para ver a la señorita Coynte saltando repetidamente sobre la cabeza de Mike o Moon, pasando por entre sus piernas, balanceándose un momento delante de él e iniciando entonces a su alrededor el movimiento circular más vertiginoso que pudiera soñar cualquier satélite astral en su órbita. (p. 71)

2 Gloria Jean Watkins, conocida como bell hooks. Este nombre, construido por la autora, es escrito por ella en minúsculas, cuestionando el canon gramatical hegemónico. 
Frente al que hacer y cómo actuar el cuerpo existe una demanda política que obliga a habitar lo corpóreo desde las diferencias de género; sin embargo, la señorita Coynte se burla y parodia dicha noción, ya desde su epíteto "señorita" (virgen, delicada, refinada...), ya desde su condición de mujer. Así, ella usa el cuerpo como estrategia de liberación de prejuicios sexuales, como lugar de enunciación y actuación, como deconstrucción de comportamientos naturalizados. La señorita Coynte, entonces, se asume como dueña de su cuerpo, lo habita, lo vive, lo reconoce como protesta a lo dicho por la hegemonía patriarcal.

Otro punto que asume la narrativa de Williams (1977) frente a la sexualidad femenina es plantear la excitación y el orgasmo como formas de comunicación, que necesariamente no implican penetración. En Inventario de Fontana Bella, se relata cómo la anciana Lisabetta, de 102 años, en un sueño de medianoche, se levanta excitada de la cama: “- ¡Sebastiano! - gritó, llevándose simultáneamente el puño a la ingle. Sebastiano era el nombre de su quinto y último marido, muerto hacía cincuenta años" (pp. 33-34).

A partir de lo anterior, los tabús frente a la sexualidad femenina son abordados y a la vez desmentidos por Williams (1977), a saber:

1. Masturbación femenina (desde dos franjas etarias: jóvenes y ancianas).

2. Excitación sexual sin penetración.

3. Placer sexual en mujeres de avanzada edad: "Al tiempo que profería esta exclamación se llevó el puño a la ingle [...], en el rostro de Lisabetta había una expresión de éxtasis". (pp. 33-34)

4. Gusto por el sexo oral: "y la señorita Coynte cayó de hinojos ante él en actitud de plegaria" (pp. 68-69).

5. Deseo y actividad sexual exacerbados: "Las horas de cierre de la tienda se hicieron muy irregulares. La señorita Coynte tenía un letrero impreso que decía HE SALIDO A ALMORZAR, y este letrero pendía a veces de la puerta a las ocho y media de la mañana" (p. 69).

\section{Bienestar económico: participación política y social, ingresos y recursos propios}

La autonomía económica es un aspecto fundamental para la participación activa de la vida social y política de cualquier ser humano. Sin embargo, la desigualdad entre hombres y mujeres respecto al acceso al mercado laboral es evidente. El poco desarrollo profesional de ellas, muchas veces por la falta de tiempo (por actividades domésticas) para capacitarse, les impide acceder a un trabajo remunerado. Pero aquellas que tienen un trabajo remunerado generalmente 
desempeñan cargos de importancia menor, de apoyo y servicio; y por "dedicarse a este tipo de trabajo, funciones o roles, las mujeres no ejercen sus derechos políticos, sociales y económicos porque son consideradas solamente como apoyos de las funciones y los roles de los hombres" (Bravo \& Calvo, 2016, p. 15).

En la obra de Williams (1977), se presentan mujeres con privilegios de clase, lo que permite leerlas como personajes fuertes emocionalmente, independientes, que saben lo que quieren, dispuestas a hacer lo que esté a su alcance, seguras, libres. Es el caso de la principessa, que buscó un esposo para que la hiciera feliz, no porque necesitara que un hombre la mantuviera, o Sabbatha, literata exitosa, que decidió mantener a un amante mucho más joven que ella, reconociendo su soledad desde el inicio de la relación. Anna, en Oriflama, es una mujer que vive sola y se vale por sí misma; la señorita Coynte crea cinco negocios fructíferos, producto de la venta de antigüedades; Horne y Elphinstone son dos empleadas profesionales.

Sin embargo, ante la libertad que produce la autonomía económica, también existe el temor de perderla: “¿Dejaría la mayor parte de sus bienes a la hermana casada, con tres hijos, o sería justa y comprendería que era Elphinstone la que necesitaba realmente protección financiera para los años venideros?" (p. 21). Elphinstone sabe que la hermana, por estar casada, no tendrá inconvenientes financieros, porque supone la subvención masculina; mientras ella, por ser una mujer soltera, está sujeta a perder la independencia que ya había alcanzado, aunque "somos dos profesionales solteras" (p. 22).

Es necesario aclarar que las protagonistas de la obra de Williams (1977) son blancas y pertenecen a una clase socioeconómica media-alta. Dichos aspectos son el eje principal del feminismo clasista y racista. Para bell hooks (2017), este tipo de feminismo ha invisibilizando la lucha de las mujeres de bajos recursos y la resistencia de las mujeres negras. De esta manera, la obra de Williams peca, en tanto ubica al lector desde una sola perspectiva feminista: la de la mujer blanca y adinerada, negando de alguna manera el compromiso de hermandad y sororidad con las mujeres en situación de precariedad material y con las mujeres afroamericanas, o las dos: negras y empobrecidas, convirtiéndolas en objeto de explotación y racismo en la sociedad relatada por Williams (1977).

A pesar de lo anterior, cabe resaltar que las mujeres de Williams (1977) tienen solvencia económica, y esto repercute significativamente en la constitución de mujeres activas, propositivas, libres, interesadas en hacerle frente a la violencia sexista permitida en diferentes institucionalidades. Al respecto, Montero (2006) afirma que "el trabajo asalariado es un elemento fundamental para la autonomía económica" (§ 2, párr. 3) de mujeres que buscan fungirse como seres autónomos en espacios que insisten en jerarquizar la vida cotidiana, mujeres que deciden tener una participación pública y política activa como una apuesta transformadora. 


\section{Feminismo, liberación hacia la igualdad: autonomía social, sexual y económica}

Ocho mujeres poseídas finaliza con el relato de Anna en Oriflama. Haciendo una relación con el objeto - Oriflama significa "bandera" - y con los acontecimientos que surgen en el relato, se hallan características del feminismo como una reinterpretación de la realidad situada en este momento histórico y cultural. Estas particularidades tienen como eje principal la autonomía que le permite al sujeto "escapar de la servidumbre de la repetición [...] dejar ser un mero producto de su psique, de su historia, y de la institución que lo ha formado" (Castoriadis, 2014, párr. 25). Se habla entonces del feminismo como una práctica que está creando nuevas concepciones de habitar en el mundo.

En una sociedad heteronormativa, la naturalización de comportamientos sexistas produce incomprensión hacia otras maneras de existencia en función de la propia aspiración: “Cuál de ellas podría decirle: 'Sí, sé de qué estás hablando, te comprendo. El aire es diferente esta mañana'" (p. 129). Desde la institucionalidad pululan voces que dicen saber el sentido del feminismo; sin embargo, desde las prácticas de socialización, el aire no es diferente porque, según Oriflama, existe "una conspiración de mediocridad en el mundo, un plan universal para excluir los resurgimientos del espíritu que pudieran estropear el aparato de relojería" (p. 130). En este caso, el aparato de relojería representa el patriarcado de consentimiento (Puleo, 2005), que no permite una reinterpretación de la realidad, una manera otra de ser con el mundo, porque los hábitos conductuales no han sido abordados desde una postura crítica y propositiva por temor a pensarse desde un lugar de enunciación diferente a lo estipulado por el constructo social.

El narrador, describiendo la situación de Anna, adentra al lector en una atmósfera patriarcal y machista relatada en metáforas de enfermedades y vestimentas: "Todo era lo mismo: enfermedad, fatiga y todos los males del cuerpo y el espíritu procedían de un corazón obligado a llevar uniforme" (p. 130). El uniforme representa un elemento normativo; es decir, la mujer debe tener un conjunto de características que la lleven a definirse desde lo patriarcal, y no desde su propia subjetividad, como sujeto autónomo y libre. Por ello, se presume la enfermedad, una dolencia del espíritu encarcelado en lo prudente, lo recatado, lo que impide a la mujer ser desde lo pensado por ella misma, como sucede en Oriflama: "Fue hacia el armario. Estaba lleno de vestidos discretos en el color y la forma, todos habían sido diseñados para camuflar y ocultar aquella anarquía del corazón" (p. 130). Sin embargo, para Anna:

Resultaba evidente que debería comprar algo nuevo [...]. Era realmente una nueva estación, ya que no un mundo nuevo [...]. — ¡Quiero ese vestido! ¡Aquel rojo que hay en el escaparate! — ¡No lo envuelva, señora! ¡Quiero ponérmelo ahora mismo! — ¡Pero si es de seda roja, un vestido para la noche, señorita! —Lo sé, pero quiero llevarlo ahora. (p. 130.) 
Para Montero (2006), el movimiento feminista le da expresión a un sujeto que "se rebela contra aspectos particulares de su condición y manifiesta las situaciones que vive y percibe como injustas" (§1, párr. 3). El vestido rojo, entonces, significa la reconquista de su identidad desde su propio criterio, situación que la lleva a sentirse liviana, ajena del producto cultural que se ha ido construyendo desde la práctica social de lo que significa ser mujer. Además, el rojo simboliza una nueva lectura de su cuerpo; Anna ahora es dueña de su cuerpo, lo ha estudiado, lo vive, lo asume desde su yo autónomo: "De pronto se decidió y empezó a moverse [...] - yo también flotaré, o acaso ya estoy flotando.Tengo dos piernas. Ningún accidente me ha privado del movimiento hacia delante- - ...]. Lanzaba destellos y más destellos. Su cuerpo avanzaba con ímpetu" (p. 133).

Así, desde la cartografía corporal de Anna, se evidencia una transformación conductual, emocional y cognitiva del personaje al darse cuenta que por el cuerpo pasan relaciones de poder que se hacen visibles en la manera de proceder. De esta manera, cuando Anna reconoce su cuerpo, también defiende su derecho a elegir, su derecho a ejercer libremente la sexualidad, evidenciada en el color del vestido, color al que se le imprimen valores de seguridad y de poder, en contraposición a la idea de mujer recatada y discreta, a la que le dicen como habitar su cuerpo.

"Se sentía un poco desorientada. Ante ella se levantaba una gigantesca estatua ecuestre. [...] Parecía que el caballo iba a pisotearla [...]; llevaba un escudo y empuñaba una espada. La actitud era fiera y autoritaria" (pp. 137-138). El patriarcado se erige como la representación de lo único verdadero y posible, desde espacios totalitarios que envuelven - desde una violencia simbólicalas dinámicas de dominación masculina a la que las mujeres también asisten.

La espada y el escudo representan los mecanismos que usa la heteronomía desde la institucionalidad, lo que implica una pérdida de autonomía, porque el sujeto se encuentra sujetado en las prácticas construidas por una sociedad determinada. Al respecto, Riveros (2017), citando a Castoriadis, afirma lo siguiente: "la heteronomía tiene que ver con el hecho de que una vez puesta una ley por la sociedad queda esa ley instalada, de manera incuestionable, de una vez y para siempre" (p. 85). Así, la estatua ecuestre, desde lo simbólico, hace referencia a lo autoritario, a la heteronomía que "pretende mostrar que la ley que la rige no puede ni debe ser modificada, o cambiada por otra" (Riveros, 2017, p. 86).

Por significaciones imaginarias sociales respecto a ser mujer, Anna se pregunta: "¿Qué arrastro detrás de mí? Veintiocho años y todas estas instituciones..." (p. 138), pregunta que implica otras: ¿son buenas y justas nuestras leyes? ¿Qué leyes debemos hacer? A ello, Castoriadis (2014) declara: "La autonomía surge, como germen, desde que la pregunta explícita e ilimitada estalla sobre las significaciones imaginarias sociales y su fundamento posible. Momento de la creación que inaugura no solo otro tipo de sociedad sino también otro tipo de individuos" (párr. 22). 
¿Es equitativa nuestra forma de habitar el mundo ante lo que significa ser hombre o mujer? Al hacer un proceso reflexivo que afecta directamente los imaginarios sociales de la heteronormatividad, se estaría en presencia de una apuesta política que le apunta a otro eidos, que busca desde lo colectivo incidir en los procesos de socialización, para que, desde allí, se construyan significaciones disímiles a la heteronomía institucionalizada.

El feminismo tiene el potencial de cambiar no solo la vida de las mujeres, sino la vida de quien busque transformarla; "una verdadera concepción de la relación entre los sexos no debe admitir los conceptos de conquistador y conquistado" (Goldman, p. 91.). En este sentido, no hay que preguntarse por un macho culpable, sino por cómo las significaciones imaginarias sociales pueden permitir una transformación coherente con las demandas históricas y contextuales del presente.

El feminismo, entonces, es una manera otra de concepción de mundo que intenta dar sentido, significado y poder a la comunidad en general, desde dinámicas que superen las formas heterónomas institucionalizadas de lo que significa ser hombre o ser mujer, y "para ello se debe tomar consciencia, entonces, de que nosotros mismos somos agentes activos de la organización social" (Riveros, 2017, p. 113), seres que tenemos la responsabilidad de pensar otras formas de ser, estar y hacer en el mundo desde una autonomía que permita ubicarnos, no desde los roles de género, sino desde la condición misma de seres humanos que habitan esta sociedad-mundo.

\section{Referencias}

Bravo, E., \& Calvo, C. (2016) Género, autonomía, empoderamiento económico y derechos de las mujeres. El Viejo, Nicaragua: Asociación para el Desarrollo Integral de la Mujer y Fundación Mujeres Financiado por la Agencia Extremeña de Cooperación Internacional para el Desarrollo. Recuperado de https://docplayer.es/60253036-Cartilla-no1-cartilla-no1-genero-autonomia-empoderamiento-economico-y-derechos-de-las-mujeres-materialde-consulta.html

Butler, J. (2002). Cuerpos que importan: sobre los límites materiales y discursivos del "sexo". Buenos Aires: Paidós.

Castoriadis, C. (2014). Poder, política, autonomía. Recuperado de https://lapeste. org/2014/01/poder-politicaautonomia-cornelius-castoriadis/

Castellanos, G. (2011). El feminismo lésbico dentro de la teoría política feminista. Crítica Contemporánea. Revista de Teoría Politica, 1, 127-145. Recuperado de http://cienciassociales.edu.uy/institutodecienciapolitica/wp-content/ uploads/sites/4/2015/09/castellanos.pdf 
De Beauvoir, S. (1981). El segundo sexo. Los hechos y los mitos. Buenos Aires: Siglo Veinte. Recuperado de https://www.segobver.gob.mx/genero/docs/ Biblioteca/El_segundo_sexo.pdf

Garaigordobil, M., \& Donado, M. (2011). Sexismo, personalidad, psicopatología y actividades de tiempo libre en adolescentes colombianos: Diferencias en función del nivel de desarrollo de la ciudad de residencia. Psicología desde el Caribe, 27(enero-junio), 85-111. Recuperado de http://rcientificas.uninorte. edu.co/index.php/psicologia/article/viewFile/3082/2130

Goldman, E. (2010). La palabra como arma. Buenos Aires: Libros de Anarre.

Kinder, S. (2017). 23 characteristics of a classy lady. Recuperado de https://empoweringwomennow.com/23-characteristics-of-a-classy-lady/

Montero, J. (2006). Feminismo: un movimiento crítico. Intervención Psicosocial, 15(2), 167-180. Recuperado de http://scielo.isciii.es/pdf/inter/v15n2/ v15n2a04.pdf

Moya, M. (2010). Significado de Faute de mieux. Recuperado de https://psicoterapeutas.eu/faute-de-mieux/

Puleo, A. (2005). El patriarcado: ¿una organización social superada? Temas para el Debate, 133, 39-42.

Ríos, I. (2010). El lenguaje: herramienta de reconstrucción del pensamiento. Razón y Palabra, 72, 1-25. Recuperado de http://www.razonypalabra.org. $\underline{\mathrm{mx} / \mathrm{N} / \mathrm{N} 72 / \text { Varia } 72 / 27 \text { Rios 72.pdf }}$

Rivera, V. (2014). El hembrismo: un mito producto de los miedos machistas. Recuperado de www.elquintopoder.cl/genero/el-hembrismo-un -mito-producto-de-los-miedos-machistas

Riveros, C. (2017). Autonomía y democracia en Cornelius Castoriadis. Mutatis Mutandis: Revista Internacional de Filosofía, 9, 83-114. Recuperado de http:// www.revistamutatismutandis.com/index.php/mutatismutandis/article/ view/156/103

Watkins, G. (2017). El feminismo es para todo el mundo. Madrid: Traficantes de Sueños. Recuperado de https://www.traficantes.net/sites/default/files/pdfs/ TDS map47 hooks web.pdf

Williams, T. (1977). Ocho mujeres poseídas. Madrid: Luis de Caralt Editor.

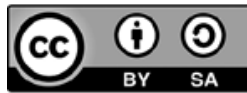

